\title{
Supply Chain Network Design Optimization Model for Multi-period Multi-product Under Uncertainty
}

\author{
M. S. Al-Ashhab ${ }^{1,2}$ \\ ${ }^{1}$ Design \& Production Engineering Dept., Faculty of Engineering, Ain-Shams University, Cairo, Egypt \\ ${ }^{2}$ Dept. of Mechanical Engineering, College of Engineering and Islamic Architecture, Umm Al-Qura University, Makkah, Kingdom Saudi \\ Arabia
}

Email address:

mohammedsem@yahoo.com,msashhab@uqu.edu.sa,mohamed_elashhab@eng.asu.edu.eg

\section{To cite this article:}

M. S. Al-Ashhab. Supply Chain Network Design Optimization Model for Multi-period Multi-product Under Uncertainty. International Journal of Mechanical Engineering and Applications. Vol. 5, No. 1, 2017, pp. 28-40. doi: 10.11648/j.ijmea.20170501.14

Received: September 4, 2016; Accepted: September 13, 2016; Published: February 17, 2017

\begin{abstract}
This research is a development of a stochastic mixed integer linear programming (SMILP) model considering stochastic customer demand, to tackle the multi-product SCND problems. It also considers multi-period, multi-echelons, products inventories, considering locations capacities and associated cost elements. The model represents both location and allocation decisions of the supply chain which maximize the total expected profit. The effect of demand mean on the total expected profit and the effect of the number of scenarios on the CPU time are studied. The results have shown the effect of customers' demands for each product in each period on the quantities of material delivered from each supplier to each factory, the quantities of products delivered from each factory and factory store to each distributor, the inventory of each product in each factory and distributor, the quantities of each type of product delivered from each distributor to each customer in each period. The model has been verified through a detailed example.
\end{abstract}

Keywords: Supply Chain Network Design (SCND), Stochastic Mixed Integer Linear Programming (SMILP), Location, Allocation, Modeling, Multi-products, Multi-echelon and Multi-periods

\section{Introduction}

Supply chain (SC) generally include two main inter-related processes of (1) production planning and inventory control that deals with production, storage, and the relation between them, and (2) logistics and distribution that determine how to transport products to customers (Ballou, R. H., [3]).

Haq, A. N. et al., proposed an integrated productioninventory-distribution model incorporating many realistic conditions to determine optimal production and distribution as well as inventory level, where a mixed-integer-linear programming (MILP) was developed to minimize the total cost of the system [5].

Maqsood, I., et al. proposed an interval-parameter fuzzy two-stage stochastic programming (IFTSP) method for the planning of water-resources-management systems under uncertainty [6].

Santoso, T., et al. proposed a stochastic programming model and solution algorithm for solving supply chain network design problems of a realistic scale. their solution methodology integrates a recently proposed sampling strategy, the sample average approximation (SAA) scheme, with an accelerated benders decomposition algorithm to quickly compute high-quality solutions to large-scale stochastic supply chain design problems with a huge (potentially infinite) number of scenarios [8].

El-Sayed, M., et al. developed a multi-period multiechelon forward-reverse logistics network design under risk model maximizing the total expected profit. The proposed network structure considers first customer zones in which the demands are stochastic and second customer zones in which the demand is assumed to be deterministic [4].

Wang, F., et al. studied a supply chain network design problem with environmental concerns. They proposed a multi-objective optimization model that captures the trade-off between the total cost and the environment influence [10].

Pishvaee, M. S., \& Razmi, J. proposed an interactive fuzzy solution approach to solve a multi-objective fuzzy mathematical programming model of an environmental 
SCND with objectives of minimizing total cost and minimization of the total environmental impact [7].

Badri, H. et al. developed a new multi-commodity SCND model with different time resolutions for strategic and tactical decisions. In addition, a mathematical technique based on the Lagrangian relaxation method was developed to solve the problem [2].

$\mathrm{Wu}$, J., \& Li, J. studied dynamic factory location and supply chain planning through minimizing the costs of factory location, path selection and transportation of coal under demand uncertainty [11].

Xia R. \& Matsukawa H. investigated a supplier-retailer supply chain that experiences disruptions in supplier during the planning horizon. While determining what suppliers, parts, processes, and transportation modes to select at each stage in the supply chain, options disruption must be considered [13].

Adabi, F., \& Omrani, H. formulated a mixed integer programming model considering two objective functions where the first one maximizes the efficiency of the supply chain and the second one minimizes the cost of facility layout as well as the production of different products [1].

Serdar E. T. \& Al-Ashhab M. S. mathematically modeled an SCN in a mixed integer linear programming (MILP) form considering deterministic demand maximizing the total profit [9].

This research is a development of a stochastic mixed integer linear programming (SMILP) model considering stochastic customer demand, to tackle the multi-product SCND problems. It also considers multi-period, multiechelons, products inventories, considering locations capacities and associated cost elements. The model represents both location and allocation decisions of the supply chain which maximize the total expected profit. The nature of the logistic decisions encompasses procurement of raw materials from suppliers, production of finished product at factories, distribution of finished product to customers via distributors, and the storage of end product at factories and distributors. The proposed scheme of supply chain consists of three echelons (three suppliers, three factories, and three distributors) to serve four customers as shown in Figure 1.

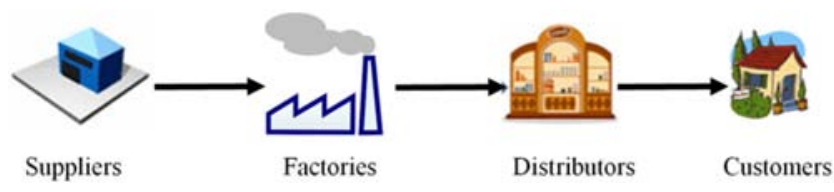

Figure 1. Supply chain network scheme.

\section{Model Assumptions and Limitations}

The problem is formulated using multi-stage stochastic mixed integer linear programming (SMILP) and it is solved using Xpress-SP software which uses Mosel language [12].

The following assumptions are considered:

a. Customers' demands are stochastic and known for all product in all periods.

b. The model is multi-product, where actions and flow of materials take place for multi-product.

c. Product weight affected material, transportation, holding

d. Costs parameters (fixed costs, material costs, manufacturing costs, non-utilized capacity costs, shortage costs, transportation costs, and inventory holding costs) are known for each location, each product at each period.

e. The shortage cost depends on the shortage quantity for each product and time.

f. The manufacturing cost depends on the manufacturing hours for each product and manufacturing cost per hours

The stochastic demand of the customers is normally distributed with mean $\mu$ and standard deviation $\sigma$, it is discretized into $\mathrm{N}$ points.

\section{Model Formulation}

The model involves the following sets, parameters, and variables:

Sets:

S, F, D, and D: potential number of suppliers, factories, distributors, and first customers,

$\mathrm{T}$ : number of periods, indexed by $\mathrm{t}$.

$\mathrm{P}$ : number of products, indexed by $\mathrm{p}$.

Parameters:

$\mathrm{F}_{\mathrm{i}}$ : fixed cost of opening location $i$,

DEMAND $_{\text {cpt }}$ : demand of customer $c$ from product $p$ in period $t$,

$\mu_{\mathrm{ct}}$ : demand mean of customer $c$ in period $t$,

$\sigma_{\mathrm{ct}}$ : demand standard deviation of customer $c$ in period $t$,

$\mathrm{P}_{\mathrm{pct}}$ : unit price of product $p$ at customer $c$ in period $t$,

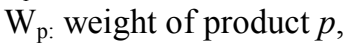

$\mathrm{MH}_{\mathrm{p}}$ : manufacturing hours for product $p$,

$\mathrm{D}_{\mathrm{sf}}$ : distance between supplier $s$ and factory $f$,

$\mathrm{D}_{\mathrm{fd}}$ : distance between factory $f$ and distributor $d$,

$\mathrm{D}_{\mathrm{dc}}$ : distance between distributor $d$ and customer $c$,

$\mathrm{CAP}_{\mathrm{st}}$ : capacity of supplier $s$ in period $t(\mathrm{~kg})$,

$\mathrm{CAPM}_{\mathrm{ft}}$ : capacity of factory $f$ Raw Material Store in period $t$

$\mathrm{CAPH}_{\mathrm{ft}}$ : capacity in manufacturing hours of factory $f$ in period $t$,

$\mathrm{CAPFS}_{\mathrm{ft}}$ : storing capacity of factory $f$ in period $t$,

$\mathrm{CAP}_{\mathrm{dt}}$ : capacity of distributor $d$ in period $t(\mathrm{~kg})$,

MatCost: material cost per unit supplied by supplier $s$ in period $t$,

$\mathrm{MC}_{\mathrm{ft}}$ : manufacturing cost per hour for factory $f$ in period $t$,

$\mathrm{MH}_{\mathrm{p}}$ : manufacturing hours for product $p$,

NUCCf: non-utilized manufacturing capacity cost per hour of factory $f$,

$\mathrm{SCPU}_{\mathrm{p}}$ : shortage cost per unit per period of product $p$,

$\mathrm{HF}_{\mathrm{p}}$ : holding cost per unit per period at factory $f$ store $(\mathrm{kg})$ of product $p$,

$\mathrm{HD}_{\mathrm{p}}$ : holding cost per unit per period at distributor $d$ store $(\mathrm{kg})$ of product $p$,

$\mathrm{B}_{\mathrm{s}}$ : batch size for supplier $s$, 
$\mathrm{B}_{\mathrm{fp} \&} \mathrm{~B}_{\mathrm{dp}}$ : batch size for factory $f$ for product $p$ and distributor $d$ for product $p$,

TCperkm: transportation cost per unit per kilometer,

M: big number,

$\mathrm{S}$ : small number.

Decision Variables:

$\mathrm{L}_{\mathrm{i}}$ : binary variable equal to 1 if a location $i$ is opened and equal to 0 otherwise,

$\mathrm{Li}_{\mathrm{ij}}$ : binary variable equal to 1 if a transportation link is activated between location $i$ location $j$,

$\mathrm{Q}_{\mathrm{ijpt}}$ : flow of batches from location $\mathrm{i}$ to location $\mathrm{j}$ of product $\mathrm{p}$ in period $\mathrm{t}$,

$\mathrm{I}_{\mathrm{fpt}}$ : flow of batches from factory $\mathrm{f}$ to its store of product $\mathrm{p}$ in period $t$,

$I_{\text {fdpt }}$ : flow of batches from the store of factory $f$ to distributor $\mathrm{d}$ of product $\mathrm{p}$ in period,

$\mathrm{R}_{\mathrm{fpt}}$ : residual inventory of the period $t$ at the store of factory f for product $\mathrm{p}$,

$\mathrm{R}_{\mathrm{dpt}}$ : residual inventory of the period $t$ at distributor $d$ for

i. Fixed Costs product $p$.

\subsection{Objective Function}

The objective of the model is to maximize the total expected profit of the supply chain network.

Total expected profit $=$ Total expected income - Total expected cost

\subsubsection{Total Expected Income}

$$
\text { Total income }=\sum_{\mathrm{d} \in \mathrm{D}} \sum_{\mathrm{c} \in \mathrm{C}} \sum_{\mathrm{p} \in \mathrm{P}} \sum_{t \in T} \mathrm{Q}_{\mathrm{dcpt}} \mathrm{B}_{\mathrm{dp}} \mathrm{P}_{\mathrm{pct}}
$$

\subsubsection{Total Expected Cost}

Total expected cost $=$ fixed costs + material costs + manufacturing costs + non-utilized capacity costs + shortage costs + transportation costs + inventory holding costs.

$$
\sum_{s \in S} F_{s} L_{s}+\sum_{f \in F} F_{f} L_{f}+\sum_{d \in D} F_{d} L_{d}
$$

ii. Material Cost

$$
\sum_{s \in S} \sum_{f \in F} \sum_{\mathrm{t} \in \mathrm{T}} \mathrm{Q}_{\mathrm{sft}} \mathrm{B}_{\mathrm{s}} \text { MatCost }_{\mathrm{st}}
$$

iii. Manufacturing Costs

$$
\sum_{f \in F} \sum_{d \in D} \sum_{p \in P} \sum_{\mathrm{t} \in \mathrm{T}} \mathrm{Q}_{\mathrm{fdpt}} \mathrm{B}_{\mathrm{fp}} \mathrm{MH}_{\mathrm{p}} \mathrm{MC}_{\mathrm{ft}}+\sum_{f \in F} \sum_{d \in D} \sum_{p \in P} \sum_{\mathrm{t} \in \mathrm{T}} \mathrm{I}_{\mathrm{fpt}} \mathrm{B}_{\mathrm{fp}} \mathrm{MH}_{\mathrm{p}} \mathrm{MC}_{\mathrm{ft}}
$$

iv. Non-Utilized Capacity Cost (for factories)

$$
\sum_{\mathrm{f} \in \mathrm{F}}\left(\sum_{p \in P} \sum_{\mathrm{t} \in \mathrm{T}}\left(\left(\mathrm{CAPH}_{\mathrm{ft}}\right) \mathrm{L}_{\mathrm{f}}-\sum_{\mathrm{d} \in \mathrm{D}}\left(\mathrm{Q}_{\mathrm{fdpt}} \mathrm{B}_{\mathrm{fp}} \mathrm{MH}_{\mathrm{p}}\right)-\sum_{\mathrm{d} \in \mathrm{D}}\left(\mathrm{I}_{\mathrm{ffpt}} \mathrm{B}_{\mathrm{fp}} \mathrm{MH}_{\mathrm{p}}\right)\right) N U C C_{f}\right)
$$

v. Shortage Cost (for distributor)

$$
\sum_{p \in P}\left(\sum_{c \in C}\left(\sum_{\mathrm{t} \in \mathrm{T}}\left(\sum_{1}^{\mathrm{t}} \mathrm{DEMAND}_{\mathrm{cpt}}-\sum_{1}^{t} \sum_{d \in D} \mathrm{Q}_{\mathrm{dcpt}} \mathrm{B}_{\mathrm{dp}}\right)\right)\right) \mathrm{SCPU}_{\mathrm{p}}
$$

vi. Transportation Costs

$$
\sum_{\mathrm{t} \in \mathrm{T}} \sum_{s \in S} \sum_{f \in F} \mathrm{Q}_{\mathrm{sft}} \mathrm{B}_{\mathrm{s}} \mathrm{T}_{\mathrm{s}} \mathrm{DS}_{\mathrm{sf}}+\sum_{p \in P}\left(\sum_{\mathrm{t} \in \mathrm{T}} \sum_{f \in F} \sum_{d \in D} \mathrm{Q}_{\mathrm{fdpt}} \mathrm{B}_{\mathrm{fp}} \mathrm{W}_{\mathrm{p}} \mathrm{T}_{\mathrm{f}} \mathrm{D}_{\mathrm{fd}}+\sum_{\mathrm{t} \in \mathrm{T}} \sum_{f \in F} \sum_{d \in D} \mathrm{I}_{\mathrm{fdpt}} \mathrm{B}_{\mathrm{fp}} \mathrm{W}_{\mathrm{p}} \mathrm{T}_{\mathrm{f}} \mathrm{D}_{\mathrm{fd}}(1+s)+\sum_{d \in D} \sum_{c \in C} \sum_{t \in T} \mathrm{Q}_{\mathrm{dcpt}} \mathrm{B}_{\mathrm{dp}} \mathrm{W}_{\mathrm{p}} \mathrm{T}_{\mathrm{d}} \mathrm{D}_{\mathrm{dc}}\right)
$$

vii. Inventory Holding Costs

$$
\sum_{p \in P}\left(\sum_{\mathrm{f} \in F} \sum_{t \in T} \mathrm{R}_{\mathrm{fpt}} \mathrm{W}_{\mathrm{p}} \mathrm{HF}_{\mathrm{f}}+\sum_{d \in D} \sum_{t \in T} \mathrm{R}_{\mathrm{dpt}} \mathrm{W}_{\mathrm{p}} \mathrm{HD}_{\mathrm{d}}\right)
$$




\subsection{Constraints}

\subsubsection{Balance Constraints}

$$
\begin{gathered}
\sum_{s \in S} Q_{s f t} B_{s}=\sum_{d \in D} \sum_{p \in P} Q_{f d p t} B_{f p} W_{p}+I_{f p t} B_{f p} W_{p}, \forall t \in T, \forall f \in F \\
I_{f p t} B_{f p}+R_{f p(t-1)} B_{f p}=R_{f p t} B_{f p}+\sum_{d \in D} I_{f d p t} B_{f p}, \forall t \in T, \forall f \in F, \forall p \in P \\
\sum_{p \in P} \sum_{f \in F}\left(Q_{f d p t}+I_{f d p t}\right) B_{f p}+R_{d p(t-1)} B_{d p}=R_{d p t} B_{d p}+\sum_{p \in P} \sum_{c \in C} Q_{d c p t} B_{d p}, \forall t \in 2 \rightarrow T, \forall d \in D \\
\sum_{d \in D} Q_{d c p t} B_{d p} \leq \operatorname{DEMAND}_{c p t}+\sum_{1 \rightarrow t} \operatorname{DEMAND}_{c p(t-1)}-\sum_{d \in D} Q_{d c p(t-1)} B_{d p}, \forall t \in T, \forall c \in C, \forall p \in P
\end{gathered}
$$

\subsubsection{Capacity Constraints}

$$
\begin{gathered}
\sum_{f \in F} \mathrm{Q}_{\mathrm{sft}} \mathrm{B}_{\mathrm{s}} \leq \mathrm{CAP}_{\mathrm{st}} \mathrm{L}_{\mathrm{s}}, \forall \mathrm{t} \in \mathrm{T}, \forall \mathrm{s} \in \mathrm{S} \\
\sum_{s \in S} \mathrm{Q}_{\mathrm{sft}} \mathrm{B}_{\mathrm{s}} \leq \mathrm{CAPM}_{\mathrm{ft}} \mathrm{L}_{\mathrm{f}}, \forall \mathrm{t} \in \mathrm{T}, \forall \mathrm{f} \in \mathrm{F} \\
\left(\sum_{\mathrm{d} \in \mathrm{D}} \mathrm{Q}_{\mathrm{fdpt}} \mathrm{B}_{\mathrm{fp}}+\sum_{\mathrm{d} \in \mathrm{D}} \mathrm{I}_{\mathrm{ffpt}} \mathrm{B}_{\mathrm{fp}}\right) \mathrm{MH}_{\mathrm{p}} \leq \mathrm{CAPH}_{\mathrm{ft}} \mathrm{L}_{\mathrm{f}}, \forall \mathrm{t} \in \mathrm{T}, \forall \mathrm{f} \in \mathrm{F}, \forall \mathrm{p} \in \mathrm{P} \\
\sum_{p \in P} \mathrm{R}_{\mathrm{fpt}} \mathrm{B}_{\mathrm{fp}} \mathrm{W}_{\mathrm{p}} \leq \mathrm{CAPFS}_{\mathrm{ft}} \mathrm{L}_{\mathrm{f}}, \forall \mathrm{t} \in \mathrm{T}, \forall \mathrm{f} \in \mathrm{F} \\
\sum_{\mathrm{f} \in \mathrm{F}}\left(\mathrm{Q}_{\mathrm{fdpt}}+\mathrm{I}_{\mathrm{fdpt}}\right) \mathrm{B}_{\mathrm{fp}} \mathrm{W}_{\mathrm{p}}+\sum_{t \in \mathrm{T}} \mathrm{R}_{\mathrm{dpt}-1} \mathrm{~B}_{\mathrm{fp}} \mathrm{W}_{\mathrm{p}} \leq \mathrm{CAP}_{\mathrm{dt}} \mathrm{L}_{\mathrm{d}}, \forall \mathrm{t} \in \mathrm{T}, \forall \mathrm{d} \in \mathrm{D}, \forall \mathrm{p} \in \mathrm{P}
\end{gathered}
$$

\section{Effect of Demand Mean and Number of Scenarios}

The relationship between demand mean and total expected profit has been studied at different values of scenarios of 1,8 , 27 and 64. Figures 2-6 show that the general shape of the relation between demand means and total expected profit is almost the same for a different number of scenarios. In general, the increase in demand mean increases the total expected profit as shown in Figure 6. The total expected profit is linearly proportional to the total demand. At transient ranges, it decreases slightly due to the shortage cost as it is not profitable to open an extra location. At certain demand mean, it is profitable to open another location to fulfill the extra demand. The same behavior continues with the increase in demand mean until the total demand exceeds the maximum permissible capacity of the network and it is not possible to open extra locations.

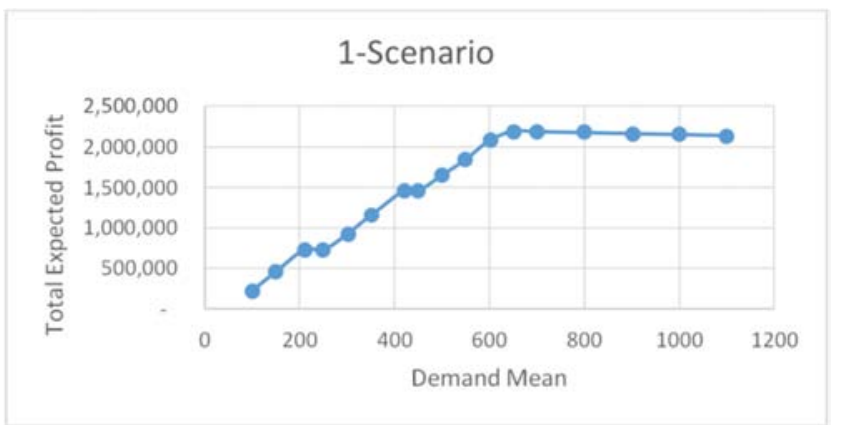

Figure 2. The relationship between demand mean and the total expected profit for 1 scenario.

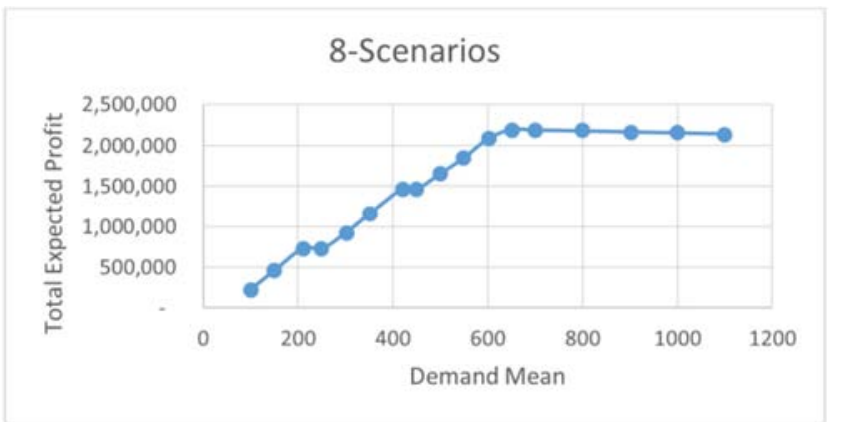

Figure 3. The Relationship between demand mean and the total expected profit for 8 scenarios. 


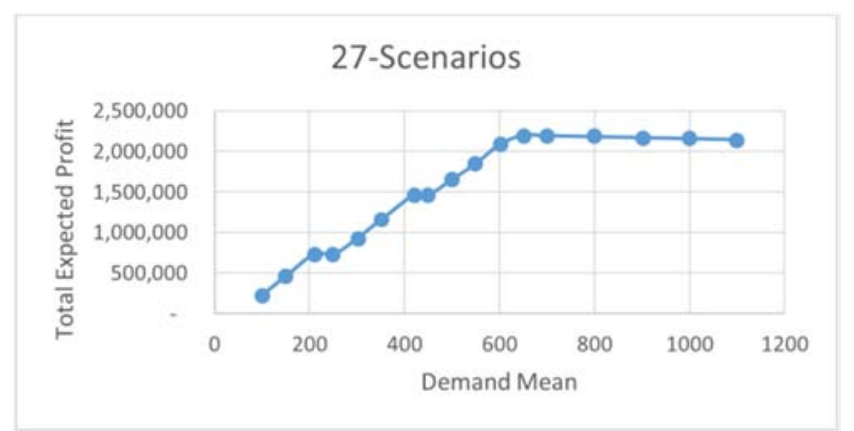

Figure 4. The Relationship between demand mean and the total expected profit for 27 scenarios.

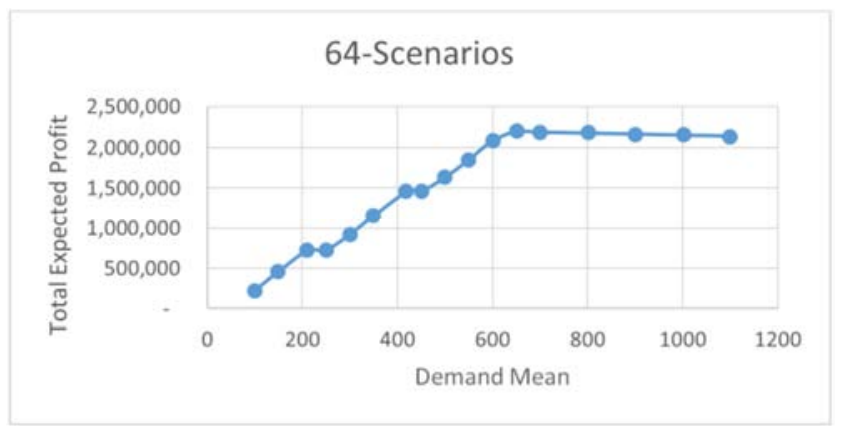

Figure 5. The Relationship between demand mean and the total expected profit for 64 scenarios.

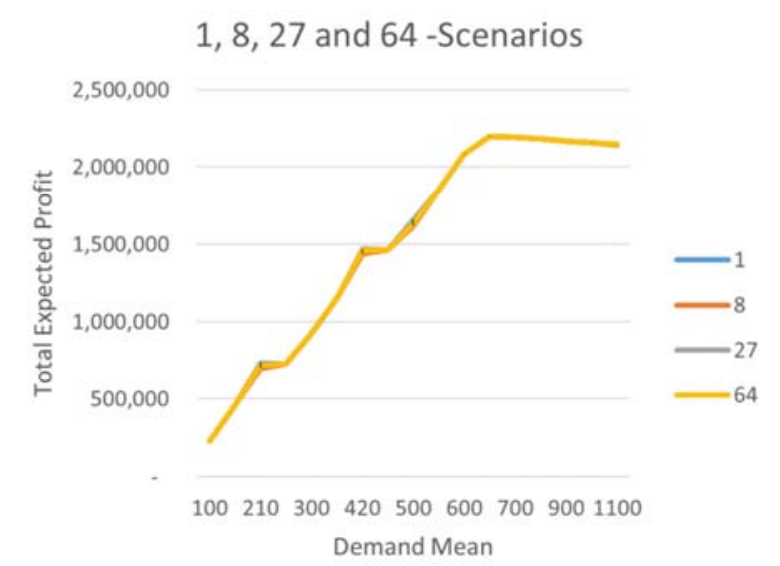

Figure 6. The Relationship between demand mean and the total expected profit for all scenarios.

The effect of changing number of scenarios on the total expected profit has been studied for different values of demand means. The changing percentage is calculated by dividing the resulted total expected profit of the given number of scenarios by the resulted total expected profit of the 1-scenario case. Figure 7 depicts the effect of the number of scenarios on the total expected profit. As it is noticed in Figure 8 the most changes happened for demand means of 200, 400 and 500 respectively which are located in the transient ranges since the increase of the total expected profit in the high demand scenarios is not equal to the decrease of it in the low demand scenarios.

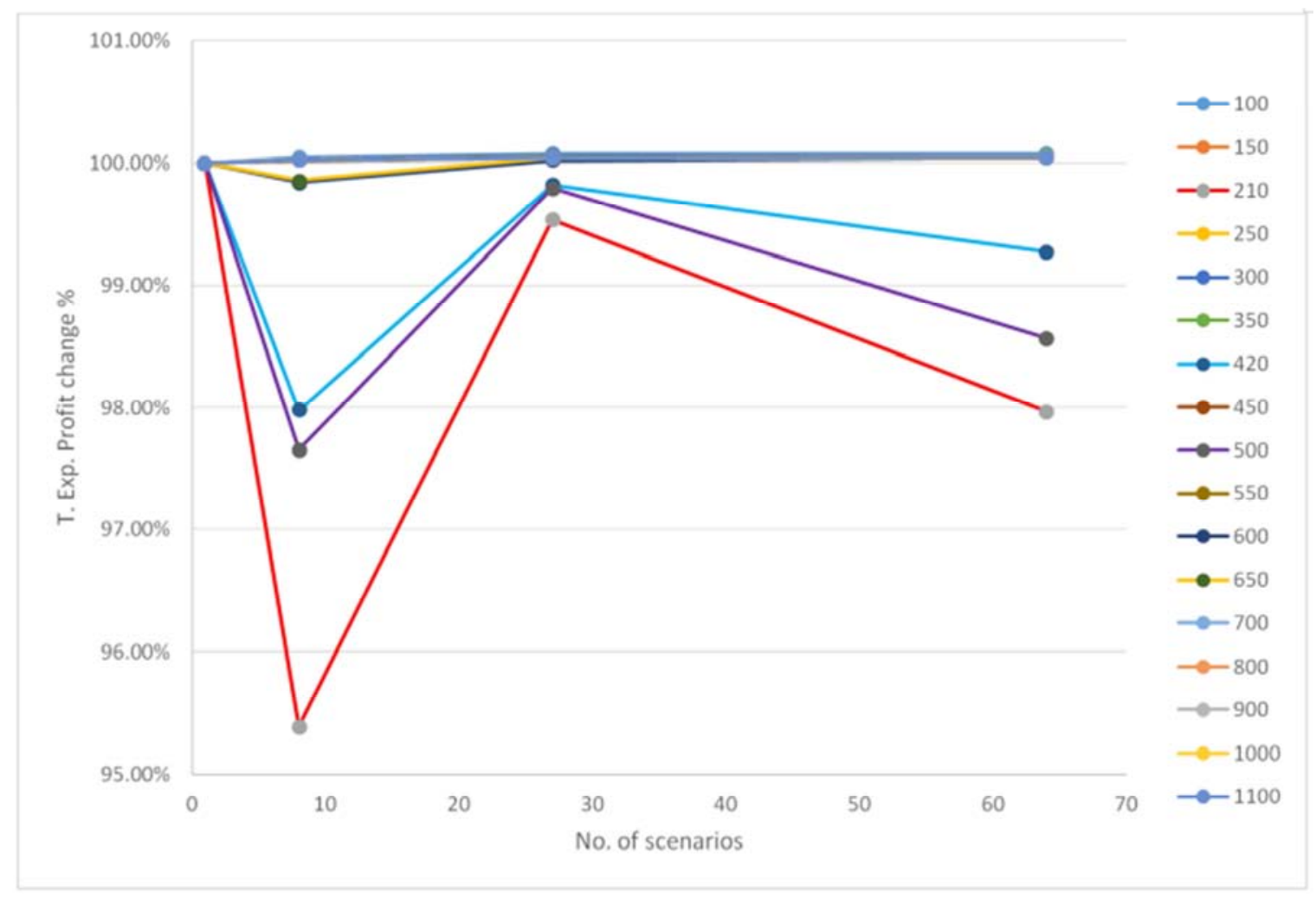

Figure 7. Effect of no. of scenarios on the total expected profit. 


\section{Total Expected profit Change \%}

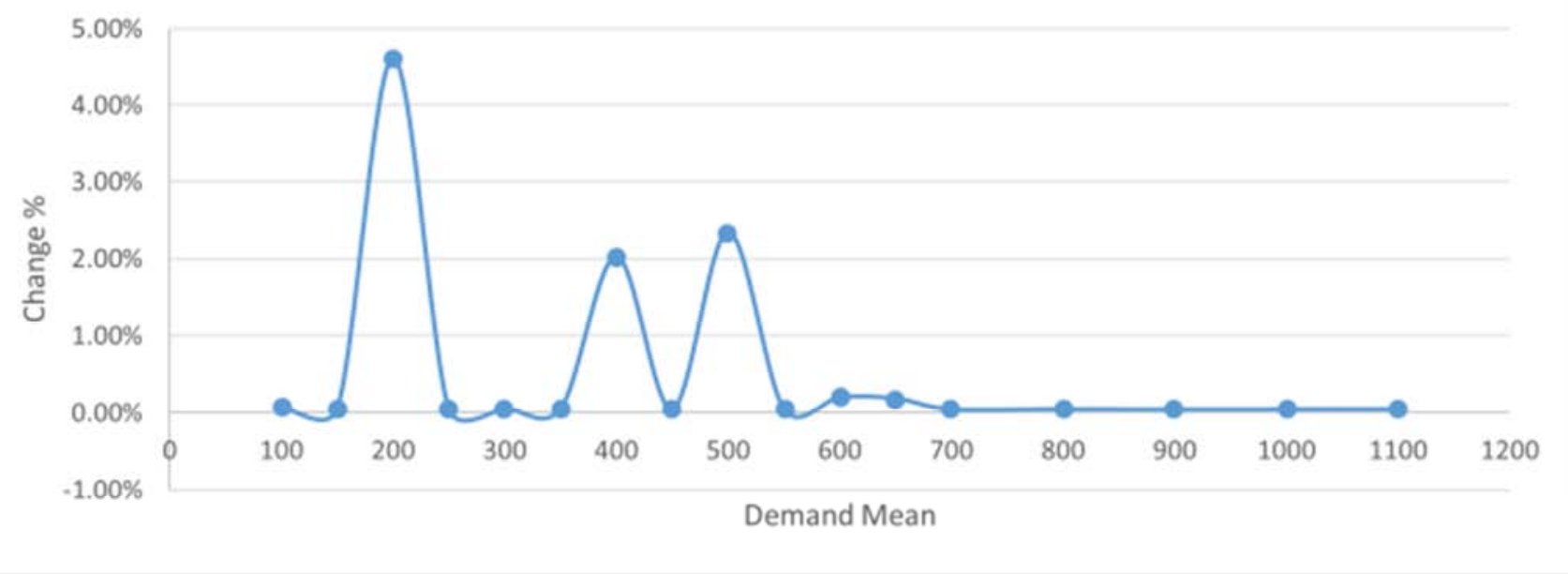

Figure 8. Maximum change percentage in total expected profit vs. demand mean.

\section{Computational Results}

In this section, we describe numerical experiment using the proposed model for solving a supply chain network design problem.

\subsection{Model Inputs}

The model has been verified through the following example where the input parameters are considered as shown in Table 1.

Table 1. Verification model parameters.

\begin{tabular}{|c|c|c|c|}
\hline Parameter & Value & Parameter & Value \\
\hline Number of suppliers & 3 & Material Cost per unit weight & 10 \\
\hline Number of factories & 3 & Manufacturing Cost per hour & 10 \\
\hline Number of Distributors & 3 & Manufacturing hours for product (1) & 1 \\
\hline Number of Customers & 4 & Manufacturing hours for product (2) & 2 \\
\hline Number of products & 3 & Manufacturing hours for product (3) & 3 \\
\hline Fixed costs for supplier $\&$ distributor & 20000 & Transportation cost per kilometer per unit & 0.001 \\
\hline Fixed costs for factory & 50000 & Factory holding cost & 2 \\
\hline Weight of Product (1) Kg & 1 & Distributor holding cost & 2 \\
\hline Weight of Product (2) Kg & 2 & Capacity of each supplier in each period & 6000 \\
\hline Weight of Product (3) Kg & 3 & Supplier batch size & 10 \\
\hline Price of Product (1) & 100 & Factory Batch size for product $p$ & 5 \\
\hline Price of Product (2) & 150 & Distributor Batch size for product $\mathrm{p}$ & 1 \\
\hline Price of Product (3) & 200 & Capacity of each Factory Raw Material Store in each period & 5000 \\
\hline Customers' Demands standard deviation & 10 & Factory capacity in hours & 5000 \\
\hline $\begin{array}{l}\text { Customers' Demands mean of all products for all customers in all } \\
\text { periods }\end{array}$ & $100-600$ & Capacity of each Factory Store in each period & 2000 \\
\hline Non-utilized cost per hour per period & 10 & Capacity of each Distributor Store in each period & 6000 \\
\hline Shortage cost of product (1) per period & 5 & Shortage cost of product (3) per period & 15 \\
\hline Shortage cost of product (2) per period & 10 & & \\
\hline
\end{tabular}

In this case, demand means and standard deviations for all customers in all periods for all products are assumed to be the same to simplify discussion, demand mean is assumed to be 200 units and demand standard deviation is assumed to be 10 units 


\subsection{Model Outputs}

In this section, the model outputs are presented. One of the outputs is the probabilities of scenarios generated by the model and they are as shown in Table 2.

Table 2. Scenarios probabilities.

\begin{tabular}{|c|c|c|c|c|c|c|c|c|c|}
\hline Scenario & Probability & Scenario & Probability & Scenario & Probability & Scenario & Probability & Scenario & Probability \\
\hline 1 & 4.0094E-12 & 26 & 2.89954E-09 & 51 & $1.94308 \mathrm{E}-08$ & 76 & 2.89954E-09 & 101 & $4.0102 \mathrm{E}-12$ \\
\hline 2 & 2.89954E-09 & 27 & $2.0969 \mathrm{E}-06$ & 52 & $1.40521 \mathrm{E}-05$ & 77 & $2.0969 \mathrm{E}-06$ & 102 & 2.90012E-09 \\
\hline 3 & $1.94308 \mathrm{E}-08$ & 28 & $1.40521 \mathrm{E}-05$ & 53 & $9.41675 \mathrm{E}-05$ & 78 & $1.40521 \mathrm{E}-05$ & 103 & $1.94347 \mathrm{E}-08$ \\
\hline 5 & $4.0102 \mathrm{E}-12$ & 30 & 2.90012E-09 & 55 & $1.94347 \mathrm{E}-08$ & 80 & 2.90012E-09 & 105 & $4.01101 \mathrm{E}-12$ \\
\hline 6 & 2.89954E-09 & 31 & $2.0969 \mathrm{E}-06$ & 56 & $1.40521 \mathrm{E}-05$ & 81 & 2.0969E-06 & 106 & 2.90012E-09 \\
\hline 7 & $2.0969 \mathrm{E}-06$ & 32 & 0.00151645 & 57 & 0.0101622 & 82 & 0.00151645 & 107 & $2.09733 \mathrm{E}-06$ \\
\hline 9 & $2.0969 \mathrm{E}-06$ & 34 & 0.00151645 & 59 & 0.0101622 & 84 & 0.00151645 & 109 & 2.09733E-06 \\
\hline 10 & 2.90012E-09 & 35 & 2.09733E-06 & 60 & 1.40549E-05 & 85 & 2.09733E-06 & 110 & 2.90071E-09 \\
\hline 11 & $1.94308 \mathrm{E}-08$ & 36 & $1.40521 \mathrm{E}-05$ & 61 & $9.41675 \mathrm{E}-05$ & 86 & $1.40521 \mathrm{E}-05$ & 111 & $1.94347 \mathrm{E}-08$ \\
\hline 12 & $1.40521 \mathrm{E}-05$ & 37 & 0.0101622 & 62 & 0.0681006 & 87 & 0.0101622 & 112 & 1.40549E-05 \\
\hline 13 & $9.41675 \mathrm{E}-05$ & 38 & 0.0681006 & 63 & 0.456365 & 88 & 0.0681006 & 113 & $9.41865 \mathrm{E}-05$ \\
\hline 14 & $1.40521 \mathrm{E}-05$ & 39 & 0.0101622 & 64 & 0.0681006 & 89 & 0.0101622 & 114 & 1.40549E-05 \\
\hline 15 & $1.94347 \mathrm{E}-08$ & 40 & 1.40549E-05 & 65 & $9.41865 \mathrm{E}-05$ & 90 & 1.40549E-05 & 115 & $1.94386 \mathrm{E}-08$ \\
\hline 16 & 2.89954E-09 & 41 & 2.0969E-06 & 66 & $1.40521 \mathrm{E}-05$ & 91 & 2.0969E-06 & 116 & 2.90012E-09 \\
\hline 18 & $1.40521 \mathrm{E}-05$ & 43 & 0.0101622 & 68 & 0.0681006 & 93 & 0.0101622 & 118 & $1.40549 \mathrm{E}-05$ \\
\hline 19 & 2.0969E-06 & 44 & 0.00151645 & 69 & 0.0101622 & 94 & 0.00151645 & 119 & $2.09733 \mathrm{E}-06$ \\
\hline 20 & 2.90012E-09 & 45 & 2.09733E-06 & 70 & 1.40549E-05 & 95 & 2.09733E-06 & 120 & $2.90071 \mathrm{E}-09$ \\
\hline 21 & $4.0102 \mathrm{E}-12$ & 46 & 2.90012E-09 & 71 & $1.94347 \mathrm{E}-08$ & 96 & 2.90012E-09 & 121 & 4.01101E-12 \\
\hline 22 & 2.90012E-09 & 47 & 2.09733E-06 & 72 & 1.40549E-05 & 97 & 2.09733E-06 & 122 & 2.90071E-09 \\
\hline 23 & $1.94347 \mathrm{E}-08$ & 48 & 1.40549E-05 & 73 & $9.41865 \mathrm{E}-05$ & 98 & $1.40549 \mathrm{E}-05$ & 123 & $1.94386 \mathrm{E}-08$ \\
\hline 24 & 2.90012E-09 & 49 & 2.09733E-06 & 74 & 1.40549E-05 & 99 & 2.09733E-06 & 124 & 2.90071E-09 \\
\hline 25 & $4.01101 \mathrm{E}-12$ & 50 & $2.90071 \mathrm{E}-09$ & 75 & $1.94386 \mathrm{E}-08$ & 100 & $2.90071 \mathrm{E}-09$ & 125 & $4.01182 \mathrm{E}-12$ \\
\hline
\end{tabular}

The model also generates the demand for each scenario according to the given distribution which is assumed to be normal in this research. Figure 9 depicts the generated scenario tree.

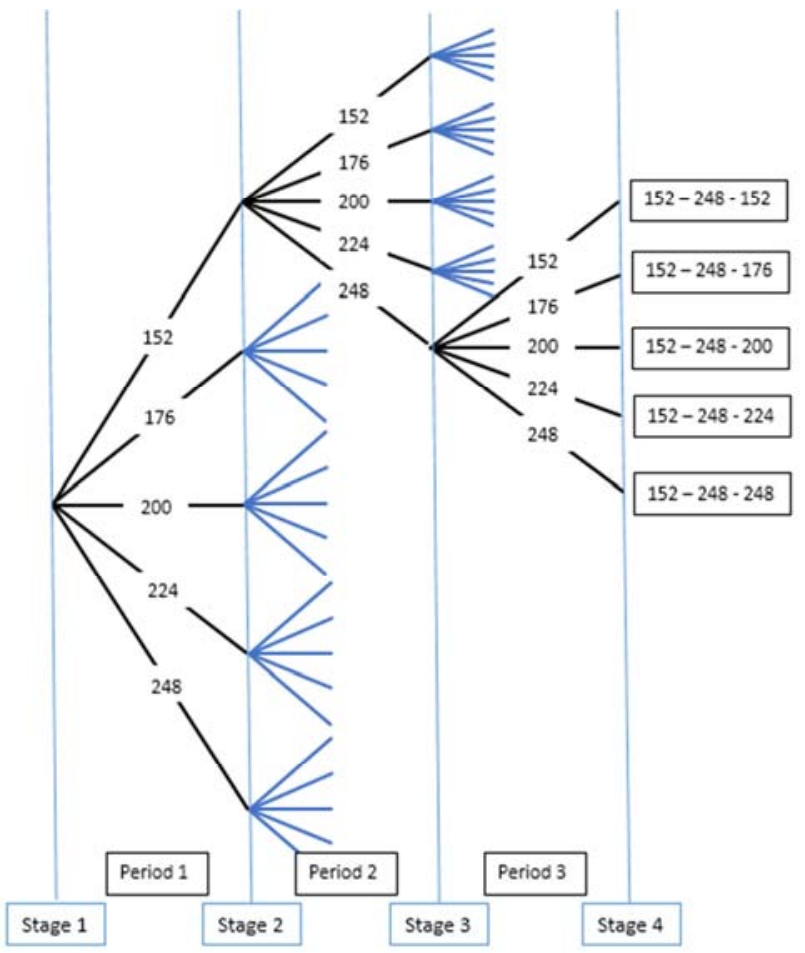

Figure 9. Scenario tree and demands.
The resulted optimal supply chain network obtained from the model is shown in Figure 10 where it is decided to open the second supplier, factory, and distributor to serve the four customers.

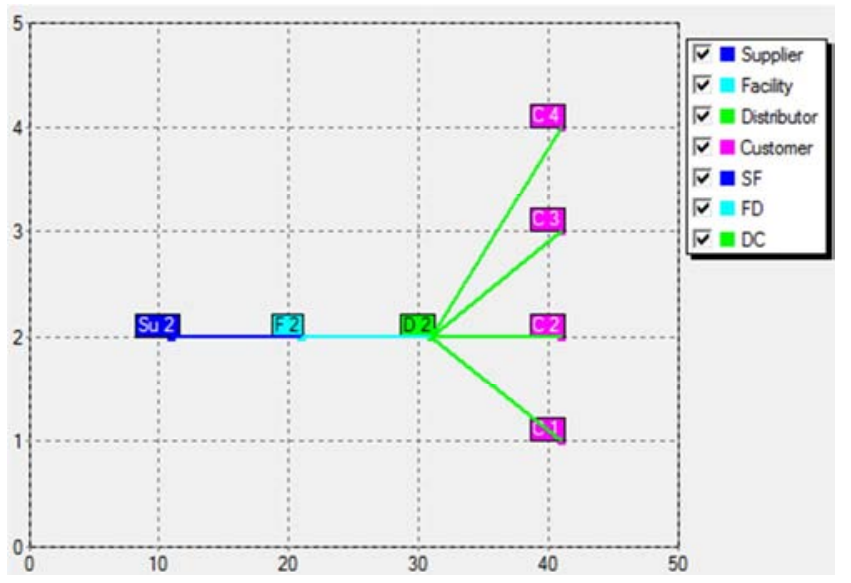

Figure 10. The Resulted Optimal Network Design.

The resulted total expected profit is 691870. Table 3 presents the number of material batches transferred from the supplier to the factory in all scenarios. Table 4 presents the number of batches transferred from the factory to the distributor from product 1 in all scenarios while the numbers of batches transferred from product 2 in all scenarios are presented Table 5, and Table 6 presents the number of batches transferred from product 3 in all scenarios. 
Table 3. Number of material batches transferred from supplier to factory in all scenarios.

\begin{tabular}{|c|c|c|c|c|c|c|c|c|c|c|c|c|c|c|c|c|c|c|c|}
\hline \multirow{2}{*}{ Scen. } & \multicolumn{3}{|l|}{ Qsft } & \multirow{2}{*}{ Scen. } & \multicolumn{3}{|l|}{ Qsft } & \multirow{2}{*}{ Scen. } & \multicolumn{3}{|l|}{ Qsft } & \multirow{2}{*}{ Scen. } & \multicolumn{3}{|l|}{ Qsft } & \multirow{2}{*}{ Scen. } & \multicolumn{3}{|l|}{ Qsft } \\
\hline & 222 & 223 & 224 & & 222 & 223 & 224 & & 222 & 223 & 224 & & 222 & 223 & 224 & & 222 & 223 & 224 \\
\hline 1 & 380 & 347 & 3 & 26 & 440 & 383 & 204 & 51 & 497 & 384 & 328 & 76 & 500 & 438 & 98 & 101 & 500 & 459 & 45 \\
\hline 2 & 380 & 347 & 199 & 27 & 440 & 383 & 386 & 52 & 497 & 384 & 385 & 77 & 500 & 438 & 385 & 102 & 500 & 459 & 149 \\
\hline 3 & 380 & 347 & 482 & 28 & 440 & 383 & 443 & 53 & 497 & 384 & 442 & 78 & 500 & 438 & 442 & 103 & 500 & 459 & 480 \\
\hline 4 & 380 & 347 & 194 & 29 & 440 & 383 & 500 & 54 & 497 & 384 & 499 & 79 & 500 & 438 & 500 & 104 & 500 & 459 & 336 \\
\hline 5 & 380 & 347 & 0 & 30 & 440 & 383 & 322 & 55 & 497 & 384 & 500 & 80 & 500 & 438 & 191 & 105 & 500 & 459 & 0 \\
\hline 6 & 380 & 443 & 221 & 31 & 440 & 440 & 329 & 56 & 497 & 443 & 326 & 81 & 500 & 496 & 327 & 106 & 500 & 500 & 138 \\
\hline 7 & 380 & 443 & 386 & 32 & 440 & 440 & 386 & 57 & 497 & 443 & 383 & 82 & 500 & 496 & 384 & 107 & 500 & 500 & 440 \\
\hline 8 & 380 & 443 & 443 & 33 & 440 & 440 & 443 & 58 & 497 & 443 & 440 & 83 & 500 & 496 & 443 & 108 & 500 & 500 & 497 \\
\hline 9 & 380 & 443 & 500 & 34 & 440 & 440 & 500 & 59 & 497 & 443 & 500 & 84 & 500 & 496 & 500 & 109 & 500 & 500 & 500 \\
\hline 10 & 380 & 443 & 370 & 35 & 440 & 440 & 500 & 60 & 497 & 443 & 500 & 85 & 500 & 496 & 499 & 110 & 500 & 500 & 164 \\
\hline 11 & 380 & 500 & 327 & 36 & 440 & 500 & 326 & 61 & 497 & 500 & 326 & 86 & 500 & 499 & 381 & 111 & 500 & 500 & 440 \\
\hline 12 & 380 & 500 & 386 & 37 & 440 & 500 & 383 & 62 & 497 & 500 & 383 & 87 & 500 & 499 & 441 & 112 & 500 & 500 & 497 \\
\hline 13 & 380 & 500 & 443 & 38 & 440 & 500 & 440 & 63 & 497 & 500 & 443 & 88 & 500 & 499 & 498 & 113 & 500 & 500 & 500 \\
\hline 14 & 380 & 500 & 500 & 39 & 440 & 500 & 500 & 64 & 497 & 500 & 500 & 89 & 500 & 499 & 500 & 114 & 500 & 500 & 500 \\
\hline 15 & 380 & 500 & 500 & 40 & 440 & 500 & 500 & 65 & 497 & 500 & 500 & 90 & 500 & 499 & 500 & 115 & 500 & 500 & 500 \\
\hline 16 & 380 & 500 & 111 & 41 & 440 & 500 & 383 & 66 & 497 & 500 & 383 & 91 & 500 & 500 & 440 & 116 & 500 & 500 & 198 \\
\hline 17 & 380 & 500 & 443 & 42 & 440 & 500 & 440 & 67 & 497 & 500 & 443 & 92 & 500 & 500 & 497 & 117 & 500 & 500 & 500 \\
\hline 18 & 380 & 500 & 500 & 43 & 440 & 500 & 500 & 68 & 497 & 500 & 500 & 93 & 500 & 500 & 500 & 118 & 500 & 500 & 500 \\
\hline 19 & 380 & 500 & 500 & 44 & 440 & 500 & 500 & 69 & 497 & 500 & 500 & 94 & 500 & 500 & 500 & 119 & 500 & 500 & 500 \\
\hline 20 & 380 & 500 & 372 & 45 & 440 & 500 & 500 & 70 & 497 & 500 & 500 & 95 & 500 & 500 & 500 & 120 & 500 & 500 & 320 \\
\hline 21 & 380 & 500 & 0 & 46 & 440 & 500 & 142 & 71 & 497 & 500 & 443 & 96 & 500 & 500 & 119 & 121 & 500 & 500 & 31 \\
\hline 22 & 380 & 500 & 253 & 47 & 440 & 500 & 500 & 72 & 497 & 500 & 500 & 97 & 500 & 500 & 500 & 122 & 500 & 500 & 407 \\
\hline 23 & 380 & 500 & 500 & 48 & 440 & 500 & 500 & 73 & 497 & 500 & 500 & 98 & 500 & 500 & 500 & 123 & 500 & 500 & 500 \\
\hline 24 & 380 & 500 & 254 & 49 & 440 & 500 & 500 & 74 & 497 & 500 & 500 & 99 & 500 & 500 & 500 & 124 & 500 & 500 & 406 \\
\hline 25 & 380 & 500 & 0 & 50 & 440 & 500 & 336 & 75 & 497 & 500 & 500 & 100 & 500 & 500 & 323 & 125 & 500 & 500 & 0 \\
\hline
\end{tabular}

Table 4. Number of batches of product 1 transferred from factory to distributor in all scenarios.

\begin{tabular}{|c|c|c|c|c|c|c|c|c|c|c|c|c|c|c|c|c|c|c|c|}
\hline \multirow{2}{*}{ Scen. } & \multicolumn{3}{|c|}{ Qfdpt22.. } & \multirow{2}{*}{ Scen. } & \multicolumn{3}{|c|}{ Qfdpt22.. } & \multirow{2}{*}{ Scen. } & \multicolumn{3}{|c|}{ Qfdpt22.. } & \multirow{2}{*}{ Scen. } & \multicolumn{3}{|c|}{ Qfdpt22.. } & \multirow{2}{*}{ Scen. } & \multicolumn{3}{|c|}{ Qfdpt22.. } \\
\hline &. .12 &. .13 &. .14 & &. .12 &. .13 &. .14 & &. .12 &. .13 &. .14 & &. .12 &. .13 &. .14 & &. .12 &. .13 &. .14 \\
\hline 1 & 123 & 120 & 0 & 26 & 141 & 122 & 90 & 51 & 178 & 104 & 53 & 76 & 179 & 121 & 29 & 101 & 196 & 122 & 0 \\
\hline 2 & 123 & 120 & 35 & 27 & 141 & 122 & 138 & 52 & 178 & 104 & 72 & 77 & 179 & 121 & 141 & 102 & 196 & 122 & 36 \\
\hline 3 & 123 & 120 & 160 & 28 & 141 & 122 & 157 & 53 & 178 & 104 & 91 & 78 & 179 & 121 & 160 & 103 & 196 & 122 & 160 \\
\hline 4 & 123 & 120 & 44 & 29 & 141 & 122 & 176 & 54 & 178 & 104 & 110 & 79 & 179 & 121 & 178 & 104 & 196 & 122 & 45 \\
\hline 5 & 123 & 120 & 0 & 30 & 141 & 122 & 76 & 55 & 178 & 104 & 123 & 80 & 179 & 121 & 50 & 105 & 196 & 122 & 0 \\
\hline 6 & 123 & 140 & 2 & 31 & 141 & 141 & 119 & 56 & 178 & 123 & 121 & 81 & 179 & 141 & 121 & 106 & 196 & 142 & 30 \\
\hline 7 & 123 & 140 & 112 & 32 & 141 & 141 & 138 & 57 & 178 & 123 & 140 & 82 & 179 & 141 & 140 & 107 & 196 & 142 & 142 \\
\hline 8 & 123 & 140 & 131 & 33 & 141 & 141 & 157 & 58 & 178 & 123 & 159 & 83 & 179 & 141 & 160 & 108 & 196 & 142 & 161 \\
\hline 9 & 123 & 140 & 150 & 34 & 141 & 141 & 176 & 59 & 178 & 123 & 179 & 84 & 179 & 141 & 179 & 109 & 196 & 142 & 180 \\
\hline 10 & 123 & 140 & 22 & 35 & 141 & 141 & 195 & 60 & 178 & 123 & 198 & 85 & 179 & 141 & 197 & 110 & 196 & 142 & 49 \\
\hline 11 & 123 & 159 & 120 & 36 & 141 & 160 & 120 & 61 & 178 & 143 & 120 & 86 & 179 & 159 & 122 & 111 & 196 & 160 & 124 \\
\hline 12 & 123 & 159 & 140 & 37 & 141 & 160 & 139 & 62 & 178 & 143 & 139 & 87 & 179 & 159 & 142 & 112 & 196 & 160 & 143 \\
\hline 13 & 123 & 159 & 159 & 38 & 141 & 160 & 158 & 63 & 178 & 143 & 159 & 88 & 179 & 159 & 161 & 113 & 196 & 160 & 162 \\
\hline 14 & 123 & 159 & 178 & 39 & 141 & 160 & 178 & 64 & 178 & 143 & 178 & 89 & 179 & 159 & 180 & 114 & 196 & 160 & 181 \\
\hline 15 & 123 & 159 & 197 & 40 & 141 & 160 & 197 & 65 & 178 & 143 & 197 & 90 & 179 & 159 & 197 & 115 & 196 & 160 & 200 \\
\hline 16 & 123 & 176 & 31 & 41 & 141 & 178 & 121 & 66 & 178 & 160 & 122 & 91 & 179 & 178 & 123 & 116 & 196 & 180 & 30 \\
\hline 17 & 123 & 176 & 142 & 42 & 141 & 178 & 140 & 67 & 178 & 160 & 142 & 92 & 179 & 178 & 142 & 117 & 196 & 180 & 142 \\
\hline 18 & 123 & 176 & 161 & 43 & 141 & 178 & 160 & 68 & 178 & 160 & 161 & 93 & 179 & 178 & 161 & 118 & 196 & 180 & 161 \\
\hline 19 & 123 & 176 & 181 & 44 & 141 & 178 & 179 & 69 & 178 & 160 & 180 & 94 & 179 & 178 & 180 & 119 & 196 & 180 & 180 \\
\hline 20 & 123 & 176 & 48 & 45 & 141 & 178 & 198 & 70 & 178 & 160 & 199 & 95 & 179 & 178 & 199 & 120 & 196 & 180 & 50 \\
\hline 21 & 123 & 148 & 0 & 46 & 141 & 145 & 74 & 71 & 178 & 179 & 123 & 96 & 179 & 198 & 31 & 121 & 196 & 199 & 0 \\
\hline 22 & 123 & 148 & 35 & 47 & 141 & 145 & 193 & 72 & 178 & 179 & 142 & 97 & 179 & 198 & 141 & 122 & 196 & 199 & 34 \\
\hline 23 & 123 & 148 & 208 & 48 & 141 & 145 & 212 & 73 & 178 & 179 & 161 & 98 & 179 & 198 & 160 & 123 & 196 & 199 & 160 \\
\hline 24 & 123 & 148 & 0 & 49 & 141 & 145 & 231 & 74 & 178 & 179 & 180 & 99 & 179 & 198 & 179 & 124 & 196 & 199 & 0 \\
\hline 25 & 123 & 148 & 0 & 50 & 141 & 145 & 94 & 75 & 178 & 179 & 199 & 100 & 179 & 198 & 47 & 125 & 196 & 199 & 0 \\
\hline
\end{tabular}


Table 5. Number of batches of product 2 transferred from factory to distributor.

\begin{tabular}{|c|c|c|c|c|c|c|c|c|c|c|c|c|c|c|c|c|c|c|c|}
\hline \multirow{2}{*}{ Scen. } & \multicolumn{3}{|c|}{ Qfdpt22.. } & \multirow{2}{*}{ Scen. } & \multicolumn{3}{|c|}{ Qfdpt22.. } & \multirow{2}{*}{ Scen. } & \multicolumn{3}{|c|}{ Qfdpt22.. } & \multirow{2}{*}{ Scen. } & \multicolumn{3}{|c|}{ Qfdpt22.. } & \multirow{2}{*}{ Scen. } & \multicolumn{3}{|c|}{ Qfdpt22.. } \\
\hline &. .22 &. .23 &. .24 & &. .22 &. .23 &. .24 & &. .22 &. .23 &. .24 & &. .22 &. .23 &. .24 & &. .22 &. .23 &. .24 \\
\hline 1 & 122 & 110 & 0 & 26 & 141 & 122 & 69 & 51 & 162 & 121 & 120 & 76 & 178 & 122 & 1 & 101 & 198 & 122 & 0 \\
\hline 2 & 122 & 110 & 0 & 27 & 141 & 122 & 107 & 52 & 162 & 121 & 139 & 77 & 178 & 122 & 112 & 102 & 198 & 122 & 29 \\
\hline 3 & 122 & 110 & 171 & 28 & 141 & 122 & 126 & 53 & 162 & 121 & 158 & 78 & 178 & 122 & 131 & 103 & 198 & 122 & 160 \\
\hline 4 & 122 & 110 & 49 & 29 & 141 & 122 & 145 & 54 & 162 & 121 & 177 & 79 & 178 & 122 & 150 & 104 & 198 & 122 & 45 \\
\hline 5 & 122 & 110 & 0 & 30 & 141 & 122 & 65 & 55 & 162 & 121 & 197 & 80 & 178 & 122 & 28 & 105 & 198 & 122 & 0 \\
\hline 6 & 122 & 141 & 46 & 31 & 141 & 141 & 106 & 56 & 162 & 140 & 120 & 81 & 178 & 142 & 121 & 106 & 198 & 141 & 0 \\
\hline 7 & 122 & 141 & 126 & 32 & 141 & 141 & 125 & 57 & 162 & 140 & 139 & 82 & 178 & 142 & 140 & 107 & 198 & 141 & 141 \\
\hline 8 & 122 & 141 & 145 & 33 & 141 & 141 & 144 & 58 & 162 & 140 & 158 & 83 & 178 & 142 & 159 & 108 & 198 & 141 & 160 \\
\hline 9 & 122 & 141 & 164 & 34 & 141 & 141 & 163 & 59 & 162 & 140 & 178 & 84 & 178 & 142 & 178 & 109 & 198 & 141 & 179 \\
\hline 10 & 122 & 141 & 98 & 35 & 141 & 141 & 182 & 60 & 162 & 140 & 197 & 85 & 178 & 142 & 198 & 110 & 198 & 141 & 135 \\
\hline 11 & 122 & 161 & 120 & 36 & 141 & 162 & 119 & 61 & 162 & 160 & 119 & 86 & 178 & 160 & 122 & 111 & 198 & 159 & 123 \\
\hline 12 & 122 & 161 & 139 & 37 & 141 & 162 & 138 & 62 & 162 & 160 & 138 & 87 & 178 & 160 & 142 & 112 & 198 & 159 & 142 \\
\hline 13 & 122 & 161 & 158 & 38 & 141 & 162 & 157 & 63 & 162 & 160 & 158 & 88 & 178 & 160 & 161 & 113 & 198 & 159 & 161 \\
\hline 14 & 122 & 161 & 177 & 39 & 141 & 162 & 177 & 64 & 162 & 160 & 177 & 89 & 178 & 160 & 179 & 114 & 198 & 159 & 180 \\
\hline 15 & 122 & 161 & 196 & 40 & 141 & 162 & 196 & 65 & 162 & 160 & 196 & 90 & 178 & 160 & 199 & 115 & 198 & 159 & 199 \\
\hline 16 & 122 & 175 & 34 & 41 & 141 & 177 & 123 & 66 & 162 & 174 & 124 & 91 & 178 & 180 & 122 & 116 & 198 & 179 & 30 \\
\hline 17 & 122 & 175 & 144 & 42 & 141 & 177 & 142 & 67 & 162 & 174 & 144 & 92 & 178 & 180 & 141 & 117 & 198 & 179 & 141 \\
\hline 18 & 122 & 175 & 163 & 43 & 141 & 177 & 162 & 68 & 162 & 174 & 163 & 93 & 178 & 180 & 160 & 118 & 198 & 179 & 160 \\
\hline 19 & 122 & 175 & 183 & 44 & 141 & 177 & 181 & 69 & 162 & 174 & 182 & 94 & 178 & 180 & 179 & 119 & 198 & 179 & 179 \\
\hline 20 & 122 & 175 & 126 & 45 & 141 & 177 & 200 & 70 & 162 & 174 & 201 & 95 & 178 & 180 & 198 & 120 & 198 & 179 & 97 \\
\hline 21 & 122 & 171 & 0 & 46 & 141 & 198 & 30 & 71 & 162 & 196 & 122 & 96 & 178 & 197 & 30 & 121 & 198 & 156 & 31 \\
\hline 22 & 122 & 171 & 129 & 47 & 141 & 198 & 141 & 72 & 162 & 196 & 141 & 97 & 178 & 197 & 143 & 122 & 198 & 156 & 78 \\
\hline 23 & 122 & 171 & 186 & 48 & 141 & 198 & 160 & 73 & 162 & 196 & 160 & 98 & 178 & 197 & 162 & 123 & 198 & 156 & 201 \\
\hline 24 & 122 & 171 & 95 & 49 & 141 & 198 & 179 & 74 & 162 & 196 & 179 & 99 & 178 & 197 & 181 & 124 & 198 & 156 & 127 \\
\hline 25 & 122 & 171 & 0 & 50 & 141 & 198 & 49 & 75 & 162 & 196 & 198 & 100 & 178 & 197 & 52 & 125 & 198 & 156 & 0 \\
\hline
\end{tabular}

Table 6. Number of batches of product 3 transferred from factory to distributor.

\begin{tabular}{|c|c|c|c|c|c|c|c|c|c|c|c|c|c|c|c|c|c|c|c|}
\hline \multirow{2}{*}{ Scen. } & \multicolumn{3}{|c|}{ Qfdpt22.. } & \multirow{2}{*}{ Scen. } & \multicolumn{3}{|c|}{ Qfdpt22.. } & \multirow{2}{*}{ Scen. } & \multicolumn{3}{|c|}{ Qfdpt22.. } & \multirow{2}{*}{ Scen. } & \multicolumn{3}{|c|}{ Qfdpt22.. } & \multirow{2}{*}{ Scen. } & \multicolumn{3}{|c|}{ Qfdpt22.. } \\
\hline &. .32 &. .33 &. .34 & &. .32 &. .33 &. .34 & &. .32 &. .33 &. .34 & &. .32 &. .33 &. .34 & &. .32 &. .33 &. .34 \\
\hline 1 & 121 & 118 & 2 & 26 & 141 & 111 & 60 & 51 & 164 & 118 & 121 & 76 & 155 & 150 & 55 & 101 & 136 & 184 & 30 \\
\hline 2 & 121 & 118 & 121 & 27 & 141 & 111 & 140 & 52 & 164 & 118 & 140 & 77 & 155 & 150 & 135 & 102 & 136 & 184 & 68 \\
\hline 3 & 121 & 118 & 154 & 28 & 141 & 111 & 159 & 53 & 164 & 118 & 159 & 78 & 155 & 150 & 154 & 103 & 136 & 184 & 160 \\
\hline 4 & 121 & 118 & 82 & 29 & 141 & 111 & 178 & 54 & 164 & 118 & 178 & 79 & 155 & 150 & 174 & 104 & 136 & 184 & 179 \\
\hline 5 & 121 & 118 & 0 & 30 & 141 & 111 & 146 & 55 & 164 & 118 & 161 & 80 & 155 & 150 & 92 & 105 & 136 & 184 & 0 \\
\hline 6 & 121 & 136 & 116 & 31 & 141 & 141 & 109 & 56 & 164 & 143 & 97 & 81 & 155 & 188 & 97 & 106 & 136 & 192 & 82 \\
\hline 7 & 121 & 136 & 136 & 32 & 141 & 141 & 128 & 57 & 164 & 143 & 116 & 82 & 155 & 188 & 116 & 107 & 136 & 192 & 152 \\
\hline 8 & 121 & 136 & 155 & 33 & 141 & 141 & 147 & 58 & 164 & 143 & 135 & 83 & 155 & 188 & 136 & 108 & 136 & 192 & 171 \\
\hline 9 & 121 & 136 & 174 & 34 & 141 & 141 & 166 & 59 & 164 & 143 & 155 & 84 & 155 & 188 & 155 & 109 & 136 & 192 & 154 \\
\hline 10 & 121 & 136 & 174 & 35 & 141 & 141 & 147 & 60 & 164 & 143 & 136 & 85 & 155 & 188 & 135 & 110 & 136 & 192 & 3 \\
\hline 11 & 121 & 173 & 98 & 36 & 141 & 172 & 98 & 61 & 164 & 179 & 98 & 86 & 155 & 173 & 132 & 111 & 136 & 174 & 170 \\
\hline 12 & 121 & 173 & 118 & 37 & 141 & 172 & 117 & 62 & 164 & 179 & 117 & 87 & 155 & 173 & 152 & 112 & 136 & 174 & 189 \\
\hline 13 & 121 & 173 & 137 & 38 & 141 & 172 & 136 & 63 & 164 & 179 & 137 & 88 & 155 & 173 & 171 & 113 & 136 & 174 & 172 \\
\hline 14 & 121 & 173 & 156 & 39 & 141 & 172 & 156 & 64 & 164 & 179 & 156 & 89 & 155 & 173 & 154 & 114 & 136 & 174 & 153 \\
\hline 15 & 121 & 173 & 137 & 40 & 141 & 172 & 137 & 65 & 164 & 179 & 137 & 90 & 155 & 173 & 135 & 115 & 136 & 174 & 134 \\
\hline 16 & 121 & 158 & 41 & 41 & 141 & 156 & 133 & 66 & 164 & 164 & 132 & 91 & 155 & 154 & 171 & 116 & 136 & 154 & 102 \\
\hline 17 & 121 & 158 & 152 & 42 & 141 & 156 & 152 & 67 & 164 & 164 & 152 & 92 & 155 & 154 & 190 & 117 & 136 & 154 & 192 \\
\hline 18 & 121 & 158 & 171 & 43 & 141 & 156 & 172 & 68 & 164 & 164 & 171 & 93 & 155 & 154 & 173 & 118 & 136 & 154 & 173 \\
\hline 19 & 121 & 158 & 151 & 44 & 141 & 156 & 153 & 69 & 164 & 164 & 152 & 94 & 155 & 154 & 154 & 119 & 136 & 154 & 154 \\
\hline 20 & 121 & 158 & 148 & 45 & 141 & 156 & 134 & 70 & 164 & 164 & 133 & 95 & 155 & 154 & 135 & 120 & 136 & 154 & 132 \\
\hline 21 & 121 & 170 & 0 & 46 & 141 & 153 & 50 & 71 & 164 & 143 & 173 & 96 & 155 & 136 & 49 & 121 & 136 & 163 & 0 \\
\hline 22 & 121 & 170 & 71 & 47 & 141 & 153 & 175 & 72 & 164 & 143 & 192 & 97 & 155 & 136 & 191 & 122 & 136 & 163 & 208 \\
\hline 23 & 121 & 170 & 140 & 48 & 141 & 153 & 156 & 73 & 164 & 143 & 173 & 98 & 155 & 136 & 172 & 123 & 136 & 163 & 146 \\
\hline 24 & 121 & 170 & 106 & 49 & 141 & 153 & 137 & 74 & 164 & 143 & 154 & 99 & 155 & 136 & 153 & 124 & 136 & 163 & 186 \\
\hline 25 & 121 & 170 & 0 & 50 & 141 & 153 & 160 & 75 & 164 & 143 & 135 & 100 & 155 & 136 & 165 & 125 & 136 & 163 & 0 \\
\hline
\end{tabular}

There are a huge amount of data representing the number of batches transferred from the distributor to customers so, the data of only first 25 scenarios are represented by the paper and the full data are represented in appendix A or through this link 
https://rive.google.com/open?id=0B448W9rNzRcPRk9iWHIPN0dQa1U. Table 7 represents the number of batches (units) transferred from the distributor to the first and second customers for the three products for only 25 scenarios and Table 8 represents the number of batches (units) transferred from the distributor to the third and fourth customers for the three products for only 25 scenarios.

Table 7. Number of batches (units) transferred from distributors to the first and second customers for the three products for only 25 scenarios.

\begin{tabular}{|c|c|c|c|c|c|c|c|c|c|c|c|c|c|c|c|c|c|c|}
\hline \multirow{2}{*}{ Scen. } & \multicolumn{2}{|c|}{ Qdept21.. } & \multicolumn{4}{|c|}{ Qdcpt21.. } & \multicolumn{2}{|c|}{ Qdcpt21.. } & \multicolumn{4}{|c|}{ Qdcpt22.. } & \multicolumn{2}{|c|}{ Qdcpt22.. } & \multicolumn{4}{|c|}{ Qdept22.. } \\
\hline &. .12 &. .13 &. .14 &. .22 &. .23 &. .24 &. .32 &. .33 &. .34 &. .12 &. .13 &. .14 &. .22 &. .23 &. .24 &. .32 &. .33 &. .34 \\
\hline 1 & 152 & 152 & 0 & 151 & 152 & 0 & 149 & 154 & 0 & 152 & 151 & 0 & 152 & 152 & 0 & 152 & 152 & 40 \\
\hline 2 & 152 & 152 & 0 & 151 & 152 & 0 & 149 & 154 & 169 & 152 & 151 & 175 & 152 & 152 & 0 & 152 & 152 & 176 \\
\hline 3 & 152 & 152 & 200 & 151 & 152 & 200 & 149 & 154 & 200 & 152 & 151 & 200 & 152 & 152 & 200 & 152 & 152 & 200 \\
\hline 4 & 152 & 152 & 0 & 151 & 152 & 0 & 149 & 154 & 0 & 152 & 151 & 220 & 152 & 152 & 219 & 152 & 152 & 221 \\
\hline 5 & 152 & 152 & 0 & 151 & 152 & 0 & 149 & 154 & 0 & 152 & 151 & 0 & 152 & 152 & 0 & 152 & 152 & 0 \\
\hline 6 & 152 & 176 & 0 & 151 & 176 & 152 & 149 & 178 & 149 & 152 & 176 & 1 & 152 & 176 & 152 & 152 & 176 & 152 \\
\hline 7 & 152 & 176 & 176 & 151 & 176 & 176 & 149 & 178 & 177 & 152 & 176 & 176 & 152 & 176 & 176 & 152 & 176 & 176 \\
\hline 8 & 152 & 176 & 199 & 151 & 176 & 200 & 149 & 178 & 200 & 152 & 176 & 200 & 152 & 176 & 200 & 152 & 176 & 200 \\
\hline 9 & 152 & 176 & 223 & 151 & 176 & 224 & 149 & 178 & 225 & 152 & 176 & 224 & 152 & 176 & 224 & 152 & 176 & 224 \\
\hline 10 & 152 & 176 & 0 & 151 & 176 & 100 & 149 & 178 & 168 & 152 & 176 & 5 & 152 & 176 & 217 & 152 & 176 & 248 \\
\hline 11 & 152 & 200 & 152 & 151 & 200 & 153 & 149 & 201 & 152 & 152 & 200 & 152 & 152 & 200 & 152 & 152 & 199 & 152 \\
\hline 12 & 152 & 200 & 176 & 151 & 200 & 176 & 149 & 201 & 176 & 152 & 200 & 176 & 152 & 200 & 176 & 152 & 199 & 177 \\
\hline 13 & 152 & 200 & 200 & 151 & 200 & 198 & 149 & 201 & 200 & 152 & 200 & 200 & 152 & 200 & 200 & 152 & 199 & 200 \\
\hline 14 & 152 & 200 & 224 & 151 & 200 & 222 & 149 & 201 & 224 & 152 & 200 & 224 & 152 & 200 & 224 & 152 & 199 & 224 \\
\hline 15 & 152 & 200 & 248 & 151 & 200 & 248 & 149 & 201 & 248 & 152 & 200 & 248 & 152 & 200 & 248 & 152 & 199 & 248 \\
\hline 16 & 152 & 224 & 0 & 151 & 224 & 0 & 149 & 227 & 0 & 152 & 224 & 0 & 152 & 206 & 170 & 152 & 224 & 0 \\
\hline 17 & 152 & 224 & 176 & 151 & 224 & 174 & 149 & 227 & 176 & 152 & 224 & 176 & 152 & 206 & 194 & 152 & 224 & 176 \\
\hline 18 & 152 & 224 & 200 & 151 & 224 & 197 & 149 & 227 & 200 & 152 & 224 & 200 & 152 & 206 & 218 & 152 & 224 & 200 \\
\hline 19 & 152 & 224 & 224 & 151 & 224 & 225 & 149 & 227 & 224 & 152 & 224 & 224 & 152 & 206 & 242 & 152 & 224 & 224 \\
\hline 20 & 152 & 224 & 0 & 151 & 224 & 248 & 149 & 227 & 248 & 152 & 224 & 240 & 152 & 206 & 134 & 152 & 224 & 248 \\
\hline 21 & 152 & 248 & 0 & 151 & 248 & 0 & 149 & 169 & 0 & 152 & 248 & 0 & 152 & 248 & 0 & 152 & 248 & 0 \\
\hline 22 & 152 & 248 & 0 & 151 & 248 & 174 & 149 & 169 & 0 & 152 & 248 & 175 & 152 & 248 & 176 & 152 & 248 & 0 \\
\hline 23 & 152 & 248 & 200 & 151 & 248 & 200 & 149 & 169 & 282 & 152 & 248 & 200 & 152 & 248 & 200 & 152 & 248 & 200 \\
\hline 24 & 152 & 248 & 0 & 151 & 248 & 0 & 149 & 169 & 306 & 152 & 248 & 0 & 152 & 248 & 0 & 152 & 248 & 224 \\
\hline 25 & 152 & 248 & 0 & 151 & 248 & 0 & 149 & 169 & 0 & 152 & 248 & 0 & 152 & 248 & 0 & 152 & 248 & 0 \\
\hline
\end{tabular}

Table 8. Number of batches (units) transferred from distributors to the third and fourth customers for the three products for only 25 scenarios.

\begin{tabular}{|c|c|c|c|c|c|c|c|c|c|c|c|c|c|c|c|c|c|c|}
\hline \multirow{2}{*}{ Scen. } & \multicolumn{2}{|c|}{ Qdcpt 23.. } & \multicolumn{4}{|c|}{ Qdcpt 23.. } & \multicolumn{2}{|c|}{ Qdept 23.. } & \multicolumn{4}{|c|}{ Qdept 24.. } & \multicolumn{2}{|c|}{ Qdept 24.. } & \multicolumn{4}{|c|}{ Qdcpt 24.. } \\
\hline &. .12 &. .13 &. .14 &. .22 &. .23 &. .24 &. .32 &. .33 &. .34 &. .12 &. .13 &. .14 &. .22 &. .23 &. .24 &. .32 &. .33 &. .34 \\
\hline 1 & 152 & 152 & 0 & 152 & 152 & 0 & 152 & 152 & 0 & 152 & 152 & 0 & 152 & 97 & 0 & 152 & 152 & 0 \\
\hline 2 & 152 & 152 & 0 & 152 & 152 & 0 & 152 & 152 & 174 & 152 & 152 & 0 & 152 & 97 & 0 & 152 & 152 & 116 \\
\hline 3 & 152 & 152 & 200 & 152 & 152 & 200 & 152 & 152 & 200 & 152 & 152 & 200 & 152 & 97 & 255 & 152 & 152 & 200 \\
\hline 4 & 152 & 152 & 0 & 152 & 152 & 26 & 152 & 152 & 0 & 152 & 152 & 0 & 152 & 97 & 0 & 152 & 152 & 219 \\
\hline 5 & 152 & 152 & 0 & 152 & 152 & 0 & 152 & 152 & 0 & 152 & 152 & 0 & 152 & 97 & 0 & 152 & 152 & 30 \\
\hline 6 & 152 & 176 & 152 & 152 & 175 & 1 & 152 & 176 & 152 & 152 & 176 & 0 & 152 & 176 & 0 & 152 & 175 & 152 \\
\hline 7 & 152 & 176 & 175 & 152 & 175 & 177 & 152 & 176 & 176 & 152 & 176 & 176 & 152 & 176 & 176 & 152 & 175 & 176 \\
\hline 8 & 152 & 176 & 199 & 152 & 175 & 200 & 152 & 176 & 200 & 152 & 176 & 200 & 152 & 176 & 200 & 152 & 175 & 200 \\
\hline 9 & 152 & 176 & 223 & 152 & 175 & 224 & 152 & 176 & 224 & 152 & 176 & 223 & 152 & 176 & 223 & 152 & 175 & 222 \\
\hline 10 & 152 & 176 & 0 & 152 & 175 & 248 & 152 & 176 & 248 & 152 & 176 & 248 & 152 & 176 & 0 & 152 & 175 & 231 \\
\hline 11 & 152 & 199 & 148 & 152 & 200 & 152 & 152 & 200 & 152 & 152 & 199 & 152 & 152 & 200 & 151 & 152 & 200 & 149 \\
\hline 12 & 152 & 199 & 176 & 152 & 200 & 176 & 152 & 200 & 176 & 152 & 199 & 176 & 152 & 200 & 175 & 152 & 200 & 176 \\
\hline 13 & 152 & 199 & 199 & 152 & 200 & 200 & 152 & 200 & 200 & 152 & 199 & 200 & 152 & 200 & 200 & 152 & 200 & 200 \\
\hline 14 & 152 & 199 & 223 & 152 & 200 & 224 & 152 & 200 & 224 & 152 & 199 & 223 & 152 & 200 & 223 & 152 & 200 & 223 \\
\hline 15 & 152 & 199 & 247 & 152 & 200 & 248 & 152 & 200 & 248 & 152 & 199 & 246 & 152 & 200 & 244 & 152 & 200 & 56 \\
\hline 16 & 152 & 224 & 0 & 152 & 224 & 0 & 152 & 171 & 205 & 152 & 215 & 155 & 152 & 224 & 0 & 152 & 218 & 0 \\
\hline 17 & 152 & 224 & 176 & 152 & 224 & 176 & 152 & 171 & 229 & 152 & 215 & 182 & 152 & 224 & 176 & 152 & 218 & 179 \\
\hline 18 & 152 & 224 & 200 & 152 & 224 & 200 & 152 & 171 & 253 & 152 & 215 & 205 & 152 & 224 & 200 & 152 & 218 & 202 \\
\hline 19 & 152 & 224 & 224 & 152 & 224 & 224 & 152 & 171 & 277 & 152 & 215 & 233 & 152 & 224 & 224 & 152 & 218 & 30 \\
\hline 20 & 152 & 224 & 0 & 152 & 224 & 0 & 152 & 171 & 244 & 152 & 215 & 0 & 152 & 224 & 248 & 152 & 218 & 0 \\
\hline 21 & 152 & 4 & 0 & 152 & 114 & 0 & 152 & 248 & 0 & 152 & 247 & 0 & 152 & 248 & 0 & 152 & 235 & 0 \\
\hline 22 & 152 & 4 & 0 & 152 & 114 & 295 & 152 & 248 & 176 & 152 & 247 & 0 & 152 & 248 & 0 & 152 & 235 & 179 \\
\hline 23 & 152 & 4 & 444 & 152 & 114 & 334 & 152 & 248 & 200 & 152 & 247 & 196 & 152 & 248 & 196 & 152 & 235 & 18 \\
\hline 24 & 152 & 4 & 0 & 152 & 114 & 358 & 152 & 248 & 0 & 152 & 247 & 0 & 152 & 248 & 117 & 152 & 235 & 0 \\
\hline 25 & 152 & 4 & 0 & 152 & 114 & 0 & 152 & 248 & 0 & 152 & 247 & 0 & 152 & 248 & 0 & 152 & 235 & 0 \\
\hline
\end{tabular}

The number of batches transferred from factory to its store $\left(\mathrm{I}_{\mathrm{fpt}}\right)$, the number of batches transferred from this store to the 
distributor $\left(\mathrm{I}_{\mathrm{fdpt}}\right)$, and the residual batches in both factory $\left(\mathrm{R}_{\mathrm{fpt}}\right)$ and distributor $\left(\mathrm{R}_{\mathrm{dpt}}\right)$ stores for the three products for the first 25 scenarios are shown in Table 9.

Table 9. Number of batches transferred from factory to its store (Ifpt), Transferred from this store to the distributor (Ifdpt) and Residual batches in both factory (Rfpt) and distributor (Rdpt) stores for the three products for only 25 scenarios.

\begin{tabular}{|c|c|c|c|c|c|c|c|c|c|c|c|c|c|c|c|c|c|c|c|c|c|c|c|c|}
\hline \multirow{2}{*}{ Scen. } & \multicolumn{2}{|c|}{ Ifpt 2} & \multicolumn{2}{|c|}{ Ifpt 2} & \multicolumn{2}{|c|}{ Ifpt 2} & \multicolumn{2}{|c|}{ Ifdpt 22 .. } & \multicolumn{2}{|c|}{ Ifdpt 22.} & \multicolumn{2}{|c|}{ Ifdpt 22 .. } & \multicolumn{2}{|c|}{ Rfpt 2.. } & \multicolumn{2}{|c|}{ Rfpt 2.. } & \multicolumn{2}{|c|}{ Rfpt 2.. } & \multicolumn{2}{|c|}{ Rdpt 2.. } & \multicolumn{2}{|c|}{ Rdpt 2.. } & \multicolumn{2}{|c|}{ Rdpt $2 \ldots$} \\
\hline & 12 & 13 & 22 & 23 & 32 & 33 & 13 & 14 & 23 & 24 & 33 & 34 & 12 & 13 & 22 & 23 & 32 & 33 & 12 & 13 & 22 & 23 & 32 & 33 \\
\hline 1 & 0 & 0 & 0 & 0 & 10 & 0 & 0 & 0 & 0 & 0 & 4 & 6 & 0 & 0 & 0 & 0 & 10 & 6 & 7 & 0 & 3 & 0 & 0 & 0 \\
\hline 2 & 0 & 0 & 0 & 0 & 10 & 0 & 0 & 0 & 0 & 0 & 4 & 6 & 0 & 0 & 0 & 0 & 10 & 6 & 7 & 0 & 3 & 0 & 0 & 0 \\
\hline 3 & 0 & 0 & 0 & 0 & 10 & 0 & 0 & 0 & 0 & 0 & 4 & 6 & 0 & 0 & 0 & 0 & 10 & 6 & 7 & 0 & 3 & 0 & 0 & 0 \\
\hline 4 & 0 & 0 & 0 & 0 & 10 & 0 & 0 & 0 & 0 & 0 & 4 & 6 & 0 & 0 & 0 & 0 & 10 & 6 & 7 & 0 & 3 & 0 & 0 & 0 \\
\hline 5 & 0 & 0 & 0 & 0 & 10 & 0 & 0 & 0 & 0 & 0 & 4 & 6 & 0 & 0 & 0 & 0 & 10 & 6 & 7 & 0 & 3 & 0 & 0 & 0 \\
\hline 6 & 0 & 28 & 0 & 14 & 10 & 0 & 0 & 28 & 0 & 14 & 5 & 5 & 0 & 28 & 0 & 14 & 10 & 5 & 7 & 3 & 3 & 5 & 0 & 0 \\
\hline 7 & 0 & 28 & 0 & 14 & 10 & 0 & 0 & 28 & 0 & 14 & 5 & 5 & 0 & 28 & 0 & 14 & 10 & 5 & 7 & 3 & 3 & 5 & 0 & 0 \\
\hline 8 & 0 & 28 & 0 & 14 & 10 & 0 & 0 & 28 & 0 & 14 & 5 & 5 & 0 & 28 & 0 & 14 & 10 & 5 & 7 & 3 & 3 & 5 & 0 & 0 \\
\hline 9 & 0 & 28 & 0 & 14 & 10 & 0 & 0 & 28 & 0 & 14 & 5 & 5 & 0 & 28 & 0 & 14 & 10 & 5 & 7 & 3 & 3 & 5 & 0 & 0 \\
\hline 10 & 0 & 28 & 0 & 14 & 10 & 0 & 0 & 28 & 0 & 14 & 5 & 5 & 0 & 28 & 0 & 14 & 10 & 5 & 7 & 3 & 3 & 5 & 0 & 0 \\
\hline 11 & 0 & 0 & 0 & 0 & 10 & 0 & 0 & 0 & 0 & 0 & 0 & 10 & 0 & 0 & 0 & 0 & 10 & 10 & 7 & 4 & 3 & 8 & 0 & 65 \\
\hline 12 & 0 & 0 & 0 & 0 & 10 & 0 & 0 & 0 & 0 & 0 & 0 & 10 & 0 & 0 & 0 & 0 & 10 & 10 & 7 & 4 & 3 & 8 & 0 & 65 \\
\hline 13 & 0 & 0 & 0 & 0 & 10 & 0 & 0 & 0 & 0 & 0 & 0 & 10 & 0 & 0 & 0 & 0 & 10 & 10 & 7 & 4 & 3 & 8 & 0 & 65 \\
\hline 14 & 0 & 0 & 0 & 0 & 10 & 0 & 0 & 0 & 0 & 0 & 0 & 10 & 0 & 0 & 0 & 0 & 10 & 10 & 7 & 4 & 3 & 8 & 0 & 65 \\
\hline 15 & 0 & 0 & 0 & 0 & 10 & 0 & 0 & 0 & 0 & 0 & 0 & 10 & 0 & 0 & 0 & 0 & 10 & 10 & 7 & 4 & 3 & 8 & 0 & 65 \\
\hline 16 & 0 & 0 & 0 & 0 & 10 & 0 & 0 & 0 & 0 & 0 & 10 & 0 & 0 & 0 & 0 & 0 & 10 & 0 & 7 & 0 & 3 & 0 & 0 & 0 \\
\hline 17 & 0 & 0 & 0 & 0 & 10 & 0 & 0 & 0 & 0 & 0 & 10 & 0 & 0 & 0 & 0 & 0 & 10 & 0 & 7 & 0 & 3 & 0 & 0 & 0 \\
\hline 18 & 0 & 0 & 0 & 0 & 10 & 0 & 0 & 0 & 0 & 0 & 10 & 0 & 0 & 0 & 0 & 0 & 10 & 0 & 7 & 0 & 3 & 0 & 0 & 0 \\
\hline 19 & 0 & 0 & 0 & 0 & 10 & 0 & 0 & 0 & 0 & 0 & 10 & 0 & 0 & 0 & 0 & 0 & 10 & 0 & 7 & 0 & 3 & 0 & 0 & 0 \\
\hline 20 & 0 & 0 & 0 & 0 & 10 & 0 & 0 & 0 & 0 & 0 & 10 & 0 & 0 & 0 & 0 & 0 & 10 & 0 & 7 & 0 & 3 & 0 & 0 & 0 \\
\hline 21 & 0 & 0 & 0 & 0 & 10 & 0 & 0 & 0 & 0 & 0 & 10 & 0 & 0 & 0 & 0 & 0 & 10 & 0 & 7 & 0 & 3 & 0 & 0 & 0 \\
\hline 22 & 0 & 0 & 0 & 0 & 10 & 0 & 0 & 0 & 0 & 0 & 10 & 0 & 0 & 0 & 0 & 0 & 10 & 0 & 7 & 0 & 3 & 0 & 0 & 0 \\
\hline 23 & 0 & 0 & 0 & 0 & 10 & 0 & 0 & 0 & 0 & 0 & 10 & 0 & 0 & 0 & 0 & 0 & 10 & 0 & 7 & 0 & 3 & 0 & 0 & 0 \\
\hline 24 & 0 & 0 & 0 & 0 & 10 & 0 & 0 & 0 & 0 & 0 & 10 & 0 & 0 & 0 & 0 & 0 & 10 & 0 & 7 & 0 & 3 & 0 & 0 & 0 \\
\hline 25 & 0 & 0 & 0 & 0 & 10 & 0 & 0 & 0 & 0 & 0 & 10 & 0 & 0 & 0 & 0 & 0 & 10 & 0 & 7 & 0 & 3 & 0 & 0 & 0 \\
\hline 26 & 1 & 1 & 0 & 33 & 11 & 0 & 0 & 2 & 0 & 33 & 10 & 1 & 1 & 2 & 0 & 33 & 11 & 1 & 1 & 3 & 1 & 4 & 1 & 0 \\
\hline
\end{tabular}

\subsection{Model Results Analysis}

Table 10 represents the mean demand and its required material weight in kilograms and the required manufacturing hours. It can be noticed that the total expected required material equals $1200 \mathrm{~kg}$ which is smaller than the supplying capacity of one supplier so it is reasonable to open only one supplier. The total expected required manufacturing hours equals 1200 hour which is smaller than the manufacturing capacity of one factory so also, it is reasonable to open only one factory and one distributor to transfer them to customers.

Table 10. Mean demand fulfillment requirements

\begin{tabular}{|c|c|c|c|c|c|}
\hline Product & Mean demand per period & Unit weight (Kg.) & Exp. Req. weight (Kg.) & Man. Hours & Exp. Req. Hours \\
\hline 1 & 200 & 1 & 200 & 1 & 200 \\
\hline 2 & 200 & 2 & 400 & 2 & 400 \\
\hline \multirow[t]{2}{*}{3} & 200 & 3 & 600 & 3 & 600 \\
\hline & & & 1200 & & 1200 \\
\hline
\end{tabular}

Considering transportation cost, the model optimally decided to open the second raw of facilities as shown in Figure 10 to reduce the total transportation cost to the four customers.

Verification of the network flow balancing is done for only the middle scenario which has the most probability. Demands of all products for all customers are 200, 200 and 200 in the three periods. Table 11 depicts the quantities of batches and weights of raw material transferred from supplier 2 to factory 2 , and the quantities of batches and weights of products transferred from factory 2 to all customers through distributor 2. Balancing is noticed in Table 11 for the transferred weights since the transferred amount from any echelon to other are the same of 14,400 kilograms. 
Table 11. No. of batches and weights transferred from the supplier to customers.

\begin{tabular}{|c|c|c|c|c|c|c|c|c|c|c|c|c|c|c|c|c|}
\hline From-To & S2-F2 & F2-D2 & & & D2C & & & D2C & & & D2C & & & D2C & & \\
\hline Period & $\mathbf{R M}$ & P1 & P2 & P3 & P1 & P2 & P3 & P1 & $\mathbf{P 2}$ & P3 & P1 & P2 & P3 & P1 & P2 & P3 \\
\hline 1 & 497 & 178 & 162 & 164 & 200 & 200 & 200 & 200 & 200 & 200 & 200 & 200 & 200 & 200 & 200 & 200 \\
\hline 2 & 500 & 143 & 160 & 179 & 200 & 200 & 200 & 200 & 200 & 200 & 200 & 200 & 200 & 200 & 200 & 200 \\
\hline 3 & 443 & 159 & 158 & 137 & 200 & 200 & 200 & 200 & 200 & 200 & 200 & 200 & 200 & 200 & 200 & 200 \\
\hline Weight (Kg.) & 14400 & 2400 & 4800 & 7200 & 600 & 1200 & 1800 & 600 & 1200 & 1800 & 600 & 1200 & 1800 & 600 & 1200 & 1800 \\
\hline Total Weights & 14400 & 14400 & & & 1440 & & & & & & & & & & & \\
\hline
\end{tabular}

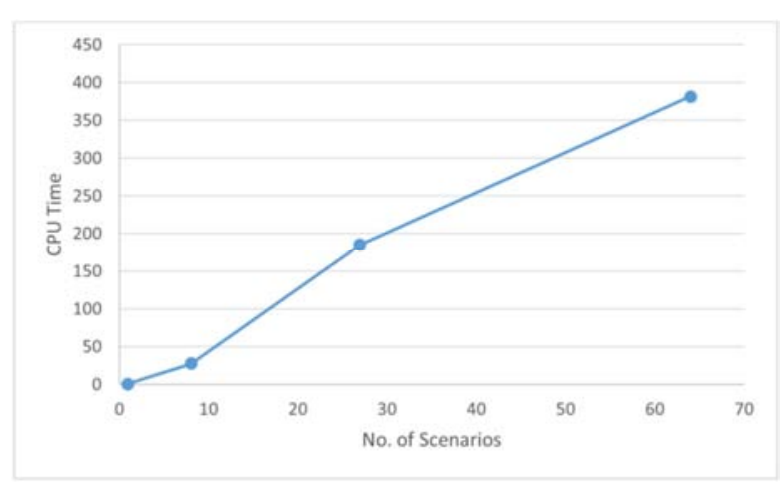

Figure 11. CPU seconds versus No. of Scenarios up to 64 scenarios.

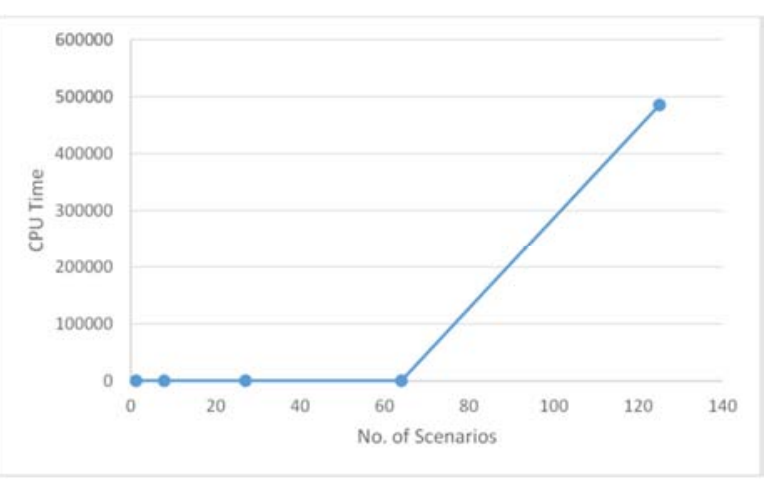

Figure 12. CPU seconds versus No. of Scenarios up to 125 scenarios.

The effect of changing the number of scenarios on the processing time is studied and it was as shown in Figures 11 and 12 from which it is noticed that increasing the number of scenarios dramatically increases CPU time. Figure 12 shows that the processing time of 125 -scenarios is too big comparing to other values. The CPU time of this example is 485,925 seconds, 135 hours or 5.6 days.

\section{Conclusion}

The proposed model is successful in designing supply chain networks while considering multi-product, multi-period stochastic demand with three echelons (suppliers, facilities, and distributors). It can only be used for single item problems. The model is flexible to solve larger problems; however, it requires more powerful hardware since the CPU time increases exponentially with the increase of the number of scenarios which increases by increasing the number of periods.

The application of the proposed model showed that the total expected profit is directly affected by demand mean for a given capacity of the network.

The proposed design model is capable of supply chain networks while considering inventory at the factory and distribution centers.

The proposed design model takes into account different types of costs like the non-utilized capacity cost for factories, transportation cost between all nodes, and the holding cost of inventory in both factories and distributors and shortage cost to enhance customers' satisfaction.

\section{References}

[1] Adabi, F., \& Omrani, H. (2015). Designing a supply chain management based on distributors' efficiency measurement. Uncertain Supply Chain Management, 3 (1), 87-96.

[2] Badri, H., Bashiri, M., \& Hejazi, T. H. (2013). Integrated strategic and tactical planning in a supply chain network design with a heuristic solution method. Computers \& Operations Research, 40 (4), 1143-1154.

[3] Ballou, R. H. (2007). Business Logistics/Supply Chain Management, 5/E (With Cd). Pearson Education India.

[4] El-Sayed, M., Afia, N., \& El-Kharbotly, A. (2010). A stochastic model for forward-reverse logistics network design under risk. Computers \& Industrial Engineering, 58 (3), 423431.

[5] Haq, A. N., Vrat, P., \& Kanda, A. (1991). An integrated production-inventory-distribution model for the manufacture of urea: a case. International Journal of production economics, $25(1), 39-49$.

[6] Maqsood, I., Huang, G. H., \& Yeomans, J. S. (2005). An interval-parameter fuzzy two-stage stochastic program for water resources management under uncertainty. European Journal of Operational Research, 167 (1), 208-225.

[7] Pishvaee, M. S., \& Razmi, J. (2012). Environmental supply chain network design using multi-objective fuzzy mathematical programming. Applied Mathematical Modelling, 36 (8), 3433-3446.

[8] Santoso, T., Ahmed, S., Goetschalckx, M., \& Shapiro, A. (2005). A stochastic programming approach for supply chain network design under uncertainty. European Journal of Operational Research, 167 (1), 96-115.

[9] Serdar E. T. \& Al-Ashhab M. S. (2016). Supply Chain Network Design Optimization Model for Multi-period Multiproduct. International Journal of Mechanical \& Mechatronics Engineering IJMME-IJENS, 16 (01), 122-140. 
[10] Wang, F., Lai, X., \& Shi, N. (2011). A multi-objective optimization for green supply chain network design. Decision Support Systems, 51 (2), 262-269.

[11] Wu, J., \& Li, J. (2014). Dynamic Coal Logistics Facility Location under Demand Uncertainty. Open Journal of Social Sciences, 2 (09), 33.
[12] www.FICO.com.

[13] Xia R. \& Matsukawa H., (2014). Optimizing the supply chain configuration with supply disruptions. Lecture Notes in Management Science, 6, 176-184. 